\title{
Effect of KOBO Extrusion and Following Cyclic Forging on Grain Refinement of Mg-9Li-2Al-0.5Sc Alloy
}

\author{
Jan Dutkiewicz ${ }^{1} \cdot$ Damian Kalita $^{1}$ D $\cdot$ Wojciech Maziarz ${ }^{1} \cdot$ Tomasz Tański $^{2} \cdot$ Wojciech Borek $^{2} \cdot$ Paweł Ostachowski $^{3}$. \\ Marek Faryna ${ }^{1}$
}

Received: 28 April 2019 / Accepted: 1 July 2019 / Published online: 13 July 2019

(c) The Author(s) 2019

\begin{abstract}
KOBO type extrusion and following cyclic forging in two perpendicular directions at temperatures $150-200{ }^{\circ} \mathrm{C}$ were applied to new Mg-9Li-2Al-0.5Sc alloy to study its effect on strength and microstructure evolution. KOBO extrusion of as cast ingot caused significant grain refinement of $(\alpha+\beta)$ dual phase $\mathrm{Mg}-9 \mathrm{Li}-2 \mathrm{Al}-0.5 \mathrm{Sc}$ alloys down to range $1-10 \mu \mathrm{m}$ for hcp $\alpha$ phase and 1-5 $\mu \mathrm{m}$ for the $\beta$ phase as resulted from EBSD studies. At that stage ultimate tensile strength UTS of $168 \mathrm{MPa}$ and elongation of $36 \%$ were attained. Additional deformation by cyclic forging alternatively from 2 perpendicular directions caused formation of much finer grains of average size of few hundred nm observed using TEM and close to $1 \mu \mathrm{m}$ applying EBSD technique. Tensile strength increased after that operation above $200 \mathrm{MPa}$ and elongation above $40 \%$, which were the highest observed in the dual phase $\mathrm{Mg}-\mathrm{Li}$ based alloys. Deformation by cyclic forging induced formation of strong texture with 0001 plane parallel to forging directions. Additional precipitates of size below $1 \mu \mathrm{m}$ at $\alpha / \beta$ interfaces or within $\beta$ phase were identified as hcp $\mathrm{AlSc}_{2}$ phase. Fine particles of hcp $\alpha$ phase were observed after severe plastic deformation SPD within $\beta$ phase grains, as effect of diffusion assisted deformation. The amount of hcp $\alpha$ phase increased after SPD up to $70 \%$ from initial $40 \%$. High density of defects at $\alpha / \beta$ interfaces on 0001 planes observed in HRTEM mode was responsible for promotion of hcp phase formation during SPD.
\end{abstract}

Keywords Magnesium alloys $\cdot \mathrm{Mg}-\mathrm{Li}-\mathrm{Al}-\mathrm{Sc} \cdot$ Severe plastic deformation $\cdot$ Transmission electron microscopy $\cdot \mathrm{Grain}$ refinement

\section{Introduction}

Magnesium-lithium alloys have recently attracted more interest for both scientific research and industrial applications because of their interesting properties, such as

Damian Kalita

d.kalita@imim.pl

Jan Dutkiewicz

j.dutkiewicz@imim.pl

1 Institute of Metallurgy and Materials Science, Polish Academy of Sciences, Reymonta 25 St., 30-059 Kraków, Poland

2 Institute of Engineering Materials and Biomaterials, Silesian University of Technology, Konarskiego St. 18a, 44-100 Gliwice, Poland

3 Faculty of Non-Ferrous Metals, AGH-University of Science and Technology, A. Mickiewicza Av. 30, 30-059 Kraków, Poland super-lightweight, relatively high specific strength, stiffness and good formability [1-4]. The magnesium-lithium alloys can reduce their density down to $1.35-1.65 \mathrm{~g} / \mathrm{cm}^{3}$ because of the addition of the lightest metal, lithium (Li), which is nearly half of the density of aluminum-based alloys. It has been shown that the addition of $\mathrm{Li}$ can lower the c/a ratio of the $\mathrm{Mg}$ crystal structure and effectively decreases the critical resolved shear stress (CRSS) required to activate additional slip systems, thus improving their ductility [1, 2]. The addition of $\mathrm{Li}$ to $\mathrm{Mg}$ alloys can transform the hexagonal close packed (hcp) structure to the body centered cubic (bcc) structure, substantially increasing the ductility of the $\mathrm{Mg}-\mathrm{Li}$ alloys and reducing their density [2-5]. The strength of dual phase alloys is lower than that for other Mg based alloys; therefore many works on ternary and quaternary additions have been performed to find the solution [6-10]. It has been found that $\mathrm{Al}$ is one of the most potential strengtheners of the $\mathrm{Mg}-\mathrm{Li}$ alloys due to the formation of coherent, metastable $\mathrm{MgAlLi}_{2}$ phase [3]. The precipitation process in $\mathrm{Mg}-\mathrm{Li}-\mathrm{Al}$ 
alloys depends upon aging parameters. Ma et al. [4] investigated the aging behavior of $\mathrm{Mg}-8 \mathrm{Li}-1 \mathrm{Al}$ and $\mathrm{Mg}-11 \mathrm{Li}-3 \mathrm{Al}$ and suggested that the increase in $\mathrm{Li}$ and $\mathrm{Al}$ contents improves the aging effect. The precipitates are mainly of the $\mathrm{MgAlLi}_{2}$ phase that is likely to coarsen during aging of the $\alpha+\beta$ two-phase alloy. In the dual phase $\mathrm{Mg}-\mathrm{Li}$-Al alloys containing up to $5 \% \mathrm{Al}$, it has been observed that Hall-Petch strengthening in ultra-fine grained alloys superimposes with strengthening as a result of alloying with $\mathrm{Al}$ (solution hardening, particulate strengthening) [11]. The superposition of these strengthening mechanisms becomes stronger with the increase of Al content, presumably due to the enhanced grain refining effect. A similar observation was reported in the squeeze cast $\beta$ phase $\mathrm{Mg}-\mathrm{Li}-\mathrm{Al}$ alloys, in which the strength increased with the $\mathrm{Al}$ content up to $5 \mathrm{wt} \%$ accompanied with a substantial decrease of grain size and the precipitation of AlLi phase [6]. A dual-phase $\mathrm{Mg}-\mathrm{Li}-\mathrm{Zn}$ alloy has been processed by a severe plastic deformation (SPD) method which is a combination of extrusion and rolling processes and enables the production of a very fine grain structure and reveals a high superplastic deformation [7, 12]. The effect of various quaternary additions like zinc [8,9], yttrium [13, 14], mischmetal [15], strontium [16], neodymium [17], silicon [18], indium [19], tin [20] and scandium [21-23] to the ternary $\mathrm{Mg}-\mathrm{Li}-\mathrm{Al}$ alloys were also studied. In most cases, except for the $\mathrm{Si}$ addition, their positive effect on mechanical properties was reported and the mechanisms of improvement of properties were related to grain refinement and second phase strengthening.

Severe plastic deformation (SPD) used for the grain refinement has been another way to improve the strength and ductility of Mg-Li alloys [25-27]. Equal Channel Angular Pressing (ECAP) has been the most popular mode of SPD leading to grain refinement in the range of $200 \mathrm{~nm}$ of the $\beta$ phase [28] up to a few $\mu \mathrm{m}[13,29-31]$. Finer grains in the range of a few hundred $\mathrm{nm}$ can be obtained using either High Pressure Torsion (HPT) [11, 20, 24] and multidirectional forging [7, 16, 32].

Considering that the HPT method, however very efficient in grain refinement can be applied only to small samples, in the presented work a multidirectional forging technique was used after the KOBO type extrusion in order to obtain high degree of working. In the KOBO technique, a combination of an extrusion process with additional plastic deformation by reversible torsion of the die allows a very high deformation at room temperature. In the case of ternary $\mathrm{Mg}-\mathrm{Li}-\mathrm{Al}$ alloy, high grain refinement, for $\alpha$ phase below $1 \mu \mathrm{m}$ and for $\beta$ phase down to $2.5 \mu \mathrm{m}$, were obtained by this technique [32]. High grain refinements in the range 4-7 $\mu \mathrm{m}$ for the AZ31 alloy [33] and below $1 \mu \mathrm{m}$ in the case of WE43 [34] alloy were also achieved with this technique. Simultaneously, an increase of YS and plasticity was observed for those alloys in comparison with conventional hot extruded alloys. In the next step, cyclic perpendicular deformation by compression at a high deformation rate (also very effective in the grain refinement of the dual phase $\mathrm{Mg}-\mathrm{Li}$ based alloys) was applied at relatively low temperature range (150-200 $\left.{ }^{\circ} \mathrm{C}\right)$ in order to limit the grain recrystallization and growth. The dual phase $\mathrm{Mg}-\mathrm{Li}-\mathrm{Al}-\mathrm{Sc}$ alloys with 2 $\mathrm{wt} \% \mathrm{Al}$ and $0.5 \mathrm{wt} \% \mathrm{Sc}$ were chosen in order to increase the recrystallization temperature and induce precipitation strengthening. The effect of alloying additions, particularly aluminum, already reported as effective in strengthening of $\mathrm{Mg}-\mathrm{Li}$ alloys was supplemented by the scandium addition that was reported positive in hcp $\alpha$ alloys but its effect was not investigated in SPD $\alpha+\beta \mathrm{Mg}-\mathrm{Li}$ based alloys. Two modes of severe plastic deformation were applied and their effect on microstructure and mechanical properties at room temperature was investigated.

\section{Experimental Procedures}

The quaternary $\mathrm{Mg}-\mathrm{Li}-\mathrm{Al}-\mathrm{Sc}$ alloy of composition $\mathrm{Mg}$, $9 \% \mathrm{Li}, 2 \% \mathrm{Al}, 0.5 \% \mathrm{Sc}$ (wt $\%$ ) were prepared from pure components: $\mathrm{Mg}$ (99.99\%), Li (99.9\%), Al (99.99\%), Sc $(99.5 \%)$ (all in wt\%). Because the alloy components greatly differed with respect to melting temperature ( $\mathrm{Li}$ $180.5^{\circ} \mathrm{C}$, Sc $1541{ }^{\circ} \mathrm{C}$ ), the preparation of alloys was divided into steps. At first, the $\mathrm{Mg}-10 \mathrm{Sc}$ (wt\%) base alloy was prepared by induction melting, next, it was added to $\mathrm{Li}, \mathrm{Al}$ and $\mathrm{Mg}$ in such a proportion that gave the desired $\mathrm{Sc}$ content in the final ternary alloy. Because liquid Li readily reacts with graphite and many ceramics, the quaternary alloys were prepared in a molybdenum crucible. The components were melted under purified argon atmosphere and cast into a steel mold of cylindrical shape of diameter $50 \mathrm{~mm}$. The mass loss of such prepared alloys was below $0.5 \%$. The castings were homogenized at $400{ }^{\circ} \mathrm{C}$ for $5 \mathrm{~h}$. Then the alloy was extruded using KOBO equipment from the bars of diameter equal to $50 \mathrm{~mm}$ down to rectangular shape of size $10 \times 10 \mathrm{~mm}$ what corresponded to the reduction coefficient $\lambda \approx 20$. The KOBO way of deformation was described in $[35,36]$. The deformation was performed by extrusion with reversibly rotating die at room temperature to avoid dynamic grain growth assuming that scandium increases the recrystallization temperature and improves the grain refinement as observed in [21-23]. Following the KOBO extrusion, the bars were again deformed by multidirectional forging using Maxstrain Gleeble equipment as described in [32]. It allowed the performance of cyclic forging in two perpendicular directions at the temperatures of $150{ }^{\circ} \mathrm{C}$ and $200{ }^{\circ} \mathrm{C}$ in the way shown in the scheme in Fig. 1b. Each forging cycle deformed the sample up to $\varepsilon=50 \%$ and followed in perpendicular direction up to the same degree of deformation and finally 10 or 20 


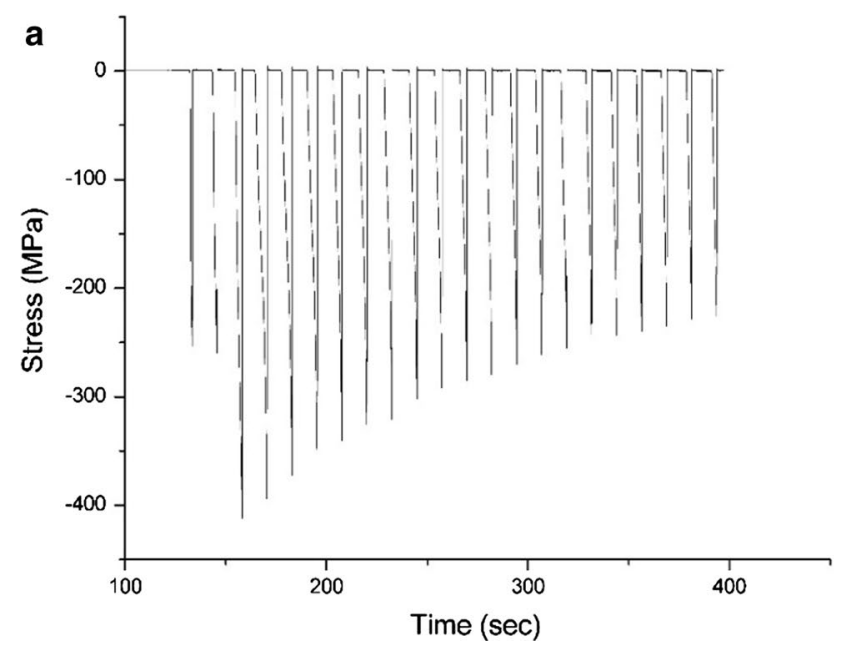

b

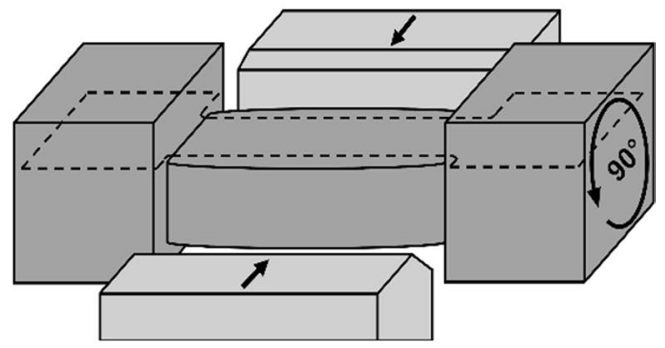

Fig. 1 a Strain/stress curves of multidirectionally forged specimen 10 times at $150{ }^{\circ} \mathrm{C}$; b Scheme showing a method of cyclic forging in a sequence of perpendicular deformations

cycles were applied at the relatively low temperatures of 150 or $200{ }^{\circ} \mathrm{C}$ to improve the plasticity but minimize the grain growth. Figure 1a shows strain/stress curves of a cyclic multidirectionally forged specimen. One can see that the compression stress decreases with increasing number of cycles from about $400 \mathrm{MPa}$ down to $250 \mathrm{MPa}$ at $150{ }^{\circ} \mathrm{C}$. The hardness of samples was tested with a Zwick ZHU 250 instrument using Vickers method and the tensile tests were performed at Shimadzu Autograph AG-X plus testing machine at room temperature and the strain rate of $10^{-4} \mathrm{~s}^{-1}$. The tensile samples were cut from multidirectionally forged material to obtain the specimen of cross section $2.5 \times 4.5 \mathrm{~mm}$ and tensile length $8.5 \mathrm{~mm}$, as shown in Fig. 1b, using an Electrical Discharge Machine (EDM) to minimize deformation effects. The microstructure of the materials was studied using an optical microscope Leica DMIRM and Scanning Electron Microscope (SEM) Philips XL30. Electron Backscatter Diffraction (EBSD) measurements were carried out on an FEI Quanta 3D FEG SEM equipped with EBSD Genesis TSL system. For each of the presented maps single dilatation cleanup routine was applied (grain tolerance angle $5^{\circ}$, minimum grain size 5 pixels). Confident index was 0.1 in all analyzed maps which means that $95 \%$ diffractions were correctly indexed. For grain size measurements the grain was defined as 10 pixels and the tolerance angle was $5^{\circ}$. The structure and composition were studied using a Transmission Electron Microscope (TEM) Tecnai FEG G2 F2O Super Twin equipped with EDAX microanalyser. Thin samples deformed with SPD were cut with the EDM, then dimpled and electropolished in electrolyte consisting of $750 \mathrm{ml}$ AR grade methanol, $150 \mathrm{ml}$ butoxyethanol, $16.74 \mathrm{~g}$ magnesium perchlorate and $7.95 \mathrm{~g}$ lithium chloride and finally dimpled using Gatan dimpler and ion beam thinned using Leica EM RES101 ion beam thinner.

\section{Results and Discussion}

Figure 2 shows tensile curves obtained of the investigated alloy after KOBO extrusion and after an additional cyclic forging at $200{ }^{\circ} \mathrm{C}$. The tensile strength of the KOBO extruded sample was equal to $160 \mathrm{MPa}$ and elongation approached 35\%. The results confirmed those ones reported in $[36,37]$ that the KOBO deformation mode improved the plastic properties of magnesium alloys and reduced the temperature of their plastic forming. The tensile curves of the samples after additional deformation by 10 or 20 cyclic forgings in two perpendicular directions showed a higher



Fig. 2 Engineering tensile curves of the sample KOBO extruded and two other additionally deformed by 10 and 20 perpendicular forging cycles at $200{ }^{\circ} \mathrm{C}$ 
yield strength (YS) and ultimate tensile strength (UTS) than those after the KOBO extrusion, however at lower elongation in the case of sample deformed in 20 cycles. One of the possible reasons for lower ductility of the samples forged 20 times is the crack formation in the material during the process, particularly in the areas adjacent to the tool edges. To reduce the risk of crack growth during the tensile test, the samples were cut only from the forged area. It is important to note, that during forging, because of the influence of elevated temperature, the precipitation of intermetallic phases occurred. It was observed in the investigated materials, that the amount of intermetallic precipitations increased with the number of cycles. Therefore, with growing number of cycles the precipitation hardening had a stronger effect on mechanical properties. It is also possible that the alloying elements like $\mathrm{Li}$ affected the crack propagation behavior. As stated in

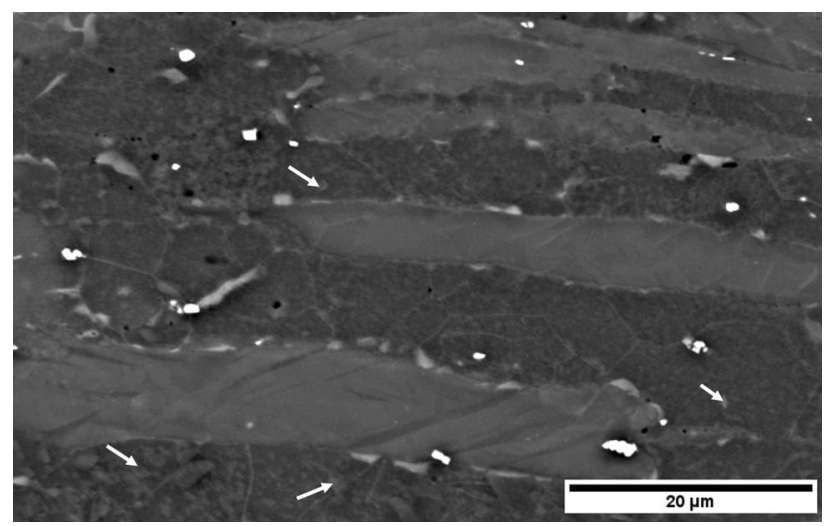

Fig. 3 SEM micrograph taken by use of backscatter electrons after KOBO type extrusion
[38], closed-shell and covalent-like bonding of $\mathrm{Mg}-\mathrm{Li}$ solute atoms would influence strong adhesion, which impeded the nucleation of a new surface at the twin boundary. Twins were observed in the hcp $\alpha$ phase in $\mathrm{Mg}-\mathrm{Li}$ based alloys $[39,40]$ and hcp $\mathrm{Mg}-\mathrm{Sc}$ ones [23] and it was likely that their presence might have contributed to the crack formation at high stress concentration places. The sample after 10 forging cycles at $200{ }^{\circ} \mathrm{C}$ showed slightly higher ductility. The improved strength after additional SPD was confirmed by hardness measurements which achieved $68 \mathrm{HV}$ after cyclic forging compared with $61 \mathrm{HV}$ directly after KOBO.

Figure 3 shows the SEM micrograph taken after the KOBO extrusion in Backscattered Electron (BSE) mode, which is sensitive to atomic contrast, i.e. changes of mean atomic number. Elongated areas of the $\alpha$ phase (visible as bright in the BSE contrast due to lower lithium content) with plate-like grains that might be either twins or subgrains can be seen as reported in $\mathrm{Mg}-\mathrm{Li}$ based alloys [38, 39]. The darker areas of the $\beta$ grains of size $5-10 \mu \mathrm{m}$ with pronounced grain boundaries are surely enriched in $\mathrm{Li}$ due to the BSE contrast. Fine slightly brighter areas within the $\beta$ grains can be seen (some of them marked by arrows), however their origin is difficult to explain basing on their contrast and size. There are also bright fine particles located often at $\alpha / \beta$ phase boundaries, where a high amount of scandium was found, however the amount of lithium could not be measured using the EDS equipment, so their identification was performed using the TEM studies. Figure 4a shows an EBSD orientation map superimposed on image quality map taken of the KOBO extruded sample with the phase image on the right side (Fig. 4b) that allows the identification of the elongated areas as the hcp $\alpha$ grains and the areas between them as the bcc $\beta$ grains. Many fine grains identified as hcp
Fig. 4 a EBSD orientation map of the KOBO extruded sample showing elongated hcp $\alpha$ grains and $\beta$ bcc grains; $\mathbf{b}$ color coded phase map along with fractions of particular phases. (Color figure online)

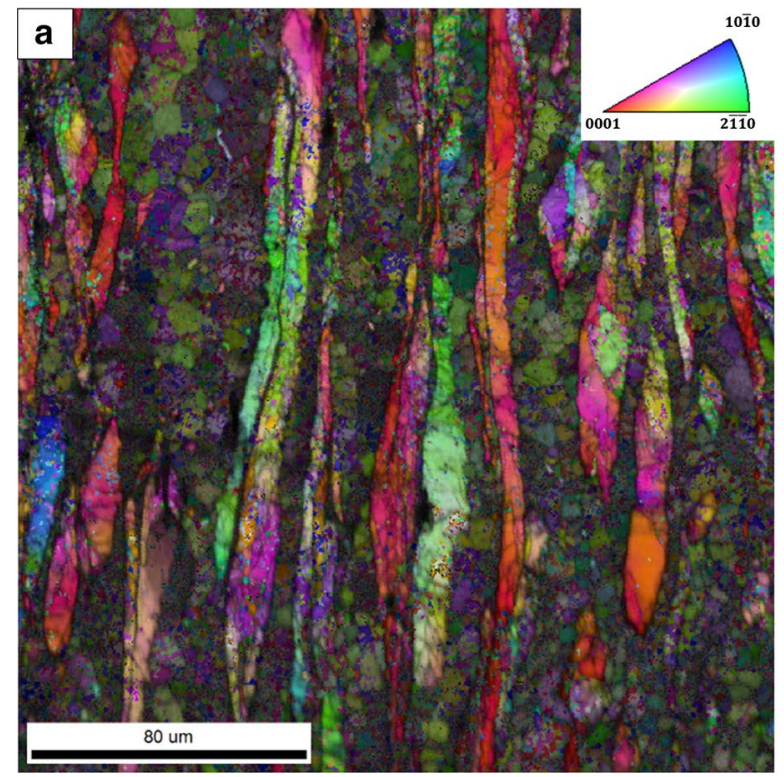

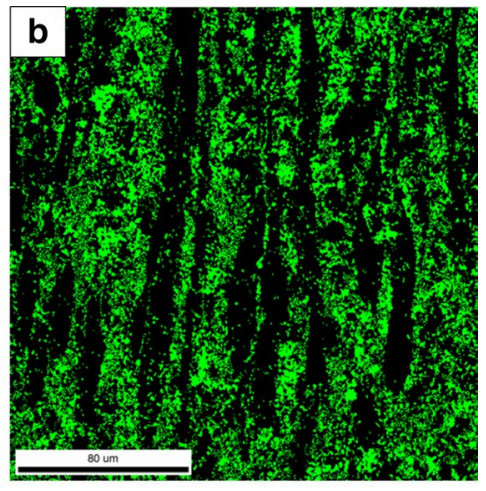

Total Partition

\section{Phase}

$\beta$ phase

$\alpha$ phase
Fraction Fraction

$0.251 \quad 0.251$

$0.749 \quad 0.749$ 
$\alpha$ were observed within the $\beta$ areas, which is in agreement with the fine brighter particles visible in the SEM image in Fig. 3. The presence of such fine hcp $\alpha$ particles was earlier reported in deformed $\beta$ phase $\mathrm{Mg}-\mathrm{Li}$ alloys [28] or dual phase $\mathrm{Mg}-\mathrm{Li}$ alloys after ECAP or multiple forging SPD [32, 35]. It is important to note that the morphologies of KOBO processed $\alpha$ and $\beta$ phases are slightly different. Due to a lower strength of the $\beta$ phase, the plastic deformation during the extrusion process occurs mainly within this phase. As a result, dynamic recrystallization is observed in this phase and equiaxed grains are formed. In addition, the observed precipitates of $\alpha$ phase in the $\beta$ areas, as well as intermetallic particles impede dislocation movements. The softer $\beta$ phase causes less intense plastic deformation of the $\alpha$ phase, therefore reducing the driving force for dynamic recrystallization in the $\alpha$ phase, which was also observed in other works [41]. Considering grain boundaries distribution shown in Figs. 4 and 5, the grain size within the $\beta$ areas seems to be higher than that within the $\alpha$ ones. The pole figures 0001 and $10 \overline{1} 0$ of hcp $\alpha$ phase and 001 and 110 of the bcc $\beta$ phase were calculated based on the EBSD measurements and shown in Fig. 5. The texture development is not too high as can be



Fig. 50001 and $10 \overline{1} 0$ pole figures of hep $\alpha$ phase $\mathbf{a}$ and 001 and 111 of the bcc $\beta$ phase $\mathbf{b}$ both calculated from EBSD measurements; $\mathbf{c}$ grain size distribution of the hcp $\alpha$ phase (left) and bcc $\beta$ phase (right) calculated from EBSD measurements assessed from the peak intensities. The 0001 maximum of the 0001 texture is rotated from the central position toward the transverse direction around the extrusion direction. It occurs most probably due to the complicated mechanism of deformation during the $\mathrm{KOBO}$ extrusion resulting from the die rotation during the process. The texture formation might be different from that observed during extrusion or rolling [42-45], where the strong 0001 texture of the $\alpha$ phase was observed and the orientation spread of the basal planes was broader towards the transverse direction as observed in [45] after rolling and annealing showing similarity to the present results. The $<10 \overline{1} 0>$ direction was often parallel to the extrusion direction after rolling and ECAP [46]. The texture of the bcc $\beta$ phase shows a slight deviation from the $\{111\}<110>$ rolling texture already reported for cubic $\mathrm{Mg}-\mathrm{Li}$ rolled alloys [44], although a $\{001\}<110>$ texture was also reported [45]. The grain size of hcp $\alpha$ phase after the KOBO extrusion was mostly $1-10 \mu \mathrm{m}$, while that of the bcc $\beta$ phase between 1 and $2 \mu \mathrm{m}$, what seems to be slightly lower than observed in the EBSD orientation map image in Fig. $4 \mathrm{a}$. The grain size measurements of the $\beta$ phase were affected by the formation of the hcp $\alpha$ phase within the $\beta$ grains, which together with large number of unsolved orientations of the $\beta$ phase make the grain size measurements not very precise. The orientation calculations of the $\alpha$ phase did not result in the identification of twins, which was surprising in view of the microstructure in Fig. 3 and works [39, 40] which reported twins in $\mathrm{Mg}-\mathrm{Li}$ and $\mathrm{Mg}-\mathrm{Sc}$ alloys. The search for twins was performed using the TEM technique.

Figure 6a shows a TEM micrograph taken after the KOBO extrusion from the $\alpha$ phase area. One can see elongated subgrains giving rather similar grey contrast changing somewhere to more dark or bright. The boundaries are not straight indicating that they are not twin boundaries, but subgrain ones as supported also by the EBSD measurements. The selected area diffraction pattern (SADP) taken of the central area of the micrograph indicated that only one grain orientation of [0110] zone axis was present confirming that the visible objects were subgrains, not twins. A different micrograph of the $\beta$ grain areas can be seen in Fig. $6 \mathrm{~b}$, where large irregular grains of size $5-10 \mu \mathrm{m}$ can be seen as observed also in SEM micrographs in Figs. 3 and 4 . The contrast changes from dark to bright within the dark grain suggest the existence of defects or fine particles of other phase with size of a few hundred $\mathrm{nm}$. The SADP from the dark area shows rather a complicated pattern that can be solved as a mixture of the bcc $\beta$ phase of [001] zone axis orientation, the hcp $\alpha$ phase of [0110] zone axis orientation and intermetallic phases formed due to the aluminum and scandium additions that were indexed as $\mathrm{Al}_{3} \mathrm{Sc}$ of [001] zone axis and $\mathrm{LiMgAl}_{2}$ with the [014] zone axis. Comparing the microstructures of hcp $\alpha$ and bcc $\beta$ phases, much more precipitates within the $\beta$ phase were recorded due to higher 

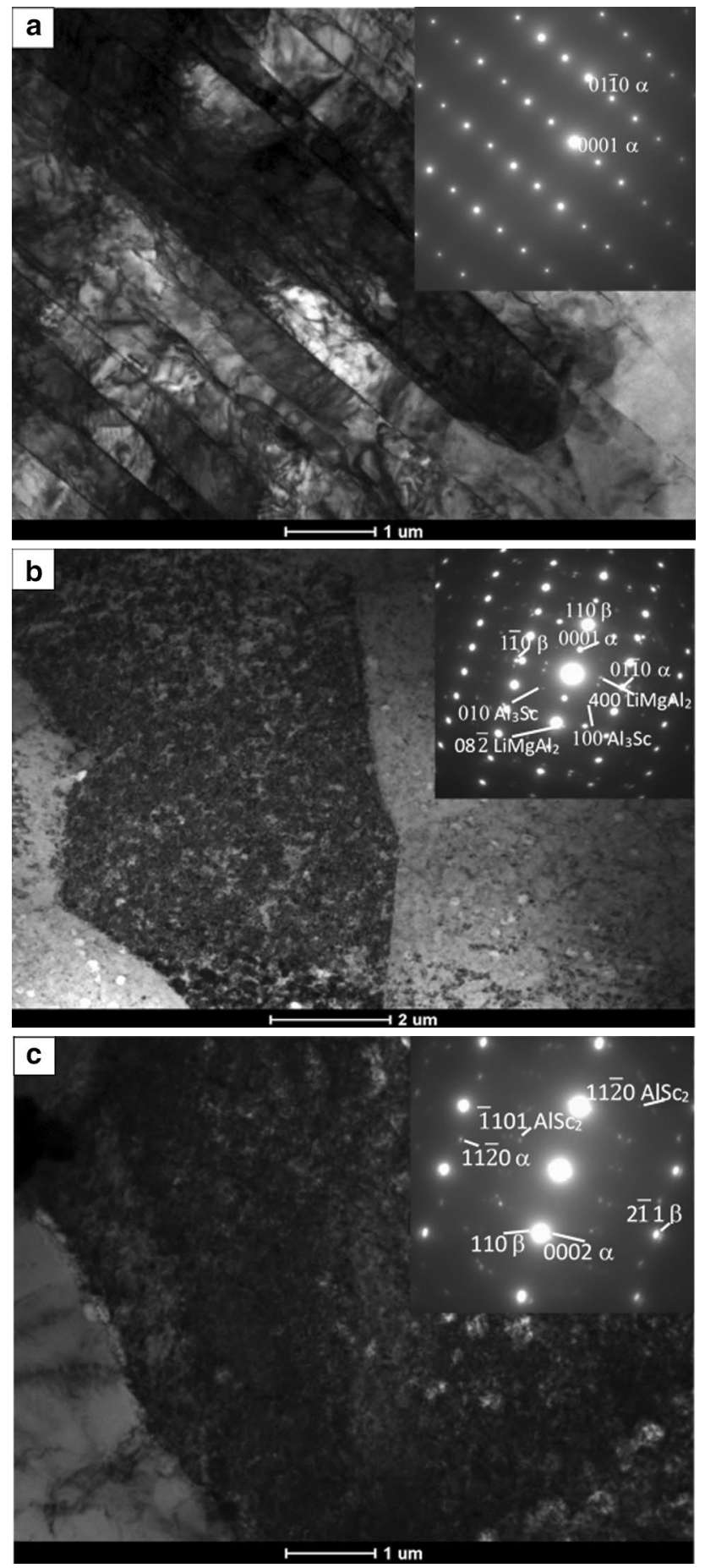

Fig. 6 TEM micrographs taken after KOBO type extrusion. a hcp $\alpha$ phase area with elongated subgrains of [0110] zone axis orientation; b [001] bcc $\beta$ phase area with $\alpha$ hcp particles of [0110] zone axis orientations, [001] $\mathrm{Al}_{3} \mathrm{Sc}$ and [014] $\mathrm{LiMgAl}_{2}$; $\mathbf{c}$ bcc $\beta$ grain of [113] orientation, hcp $\alpha$ particles of [1100] zone axis orientation and $\mathrm{AlSc}_{2}$ of $[\overline{1} 10 \overline{2}]$ zone axis orientations

content of lithium and scandium. The existence of fine particles of the hcp $\alpha$ phase after the ECAP deformation was already observed in the $\mathrm{Mg}-\mathrm{Li}$ based $\beta$ phase alloy with $14 \%$
$\mathrm{Li}$ and $1 \% \mathrm{Al}[28]$ and in the dual phase $\mathrm{Mg}-\mathrm{Li}-\mathrm{Al}$ alloys after the ECAP or multiple forging SPD [25, 32, 35]. The origin of this phase is not well understood, however it may be possible that during severe plastic deformation, diffusion assisted $\alpha$ phase formation was initiated on frequent crystal defects within the $\beta$ phase which as softer one carries most of sample deformation during either ECAP or KOBO processing and consequently the $\alpha$ phase particles form in the whole volume of $\beta$ grains. The formation of the $\alpha$ phase is most probably assisted by local diffusion of lithium out of the $\alpha$ phase, since these areas within the $\beta$ phase are slightly brighter in the BSE contrast visible in Fig. 3.

In Fig. $6 c$ dark bcc $\beta$ grain with brighter particles and a high dislocation density can be seen. The SADP was indexed as bcc $\beta$ grain of [1113] zone axis and the presence of hcp $\alpha$ particles of [1100] zone axis orientation was conformed. In addition, the $\mathrm{AlSc}_{2}$ precipitates of $[\overline{1} 10 \overline{2}]$ zone axis orientation were indexed. Comparing the structure of precipitates in the $\mathrm{Mg}-\mathrm{Li}-\mathrm{Al}$ based alloys of $\beta$ or $\alpha+\beta$ phases, it was found that mainly $\mathrm{MgLiAl}_{2}$ or AlLi phases were identified in $[16,28,46]$. In the present case apart from the $\mathrm{MgLiAl}_{2}$, also aluminum-scandium phases were observed, which suggested increased tendency to the formation of intermetallic phases what should have increased the strength of the alloys.

Figure 7 shows a high resolution transmission electron micrograph HRTEM, in which the presence of the $\beta$ phase is manifested by cross grating of perpendicular $\{110\} \beta$ lattice planes indicating its [001] zone axis orientation. In the upper part of the micrograph in Fig. 7 the double space periodicity fringes parallel to $\{110\}$ planes appear in a relatively large area. Fast Fourier transform FFT from these fragments of HRTEM images (marked by squares in Fig. 7) helped identify the $\alpha$ phase of [0110] zone axis orientation confirming earlier interpretation of the diffraction pattern in Fig. 6b. Frequent defects manifested by a loss of periodicity near the interface express their role in the $\beta \rightarrow \alpha$ transformation. Many crystal defects can be seen at the interface of both areas, indicating the important role of deformation in the formation of the hcp $\alpha$ phase within the $\beta$ grains. Although the KOBO extrusion was performed at RT, an increase of temperature could not be excluded and one can assume that the formation of the hcp $\alpha$ phase was temperature assisted as suggested also in previous works [25, 27, 28, 32], in which the elevated temperature deformation was applied.

Figure 8 contains the SEM micrographs of the KOBO extruded samples deformed additionally with 20 forging cycles at $150{ }^{\circ} \mathrm{C}$ (a) and $200{ }^{\circ} \mathrm{C}$ (b). In comparison with those only after KOBO processing the shape of $\alpha$ phase areas changed into wavy ones, composed of fine grains of size below $1 \mu \mathrm{m}$ as can be evaluated from the $\mathrm{Z}$ contrast change. The $\beta$ areas are visible as slightly darker in the BSE contrast due to higher lithium content. Similarly to these after the KOBO extrusion, in which fine, slightly brighter grey 


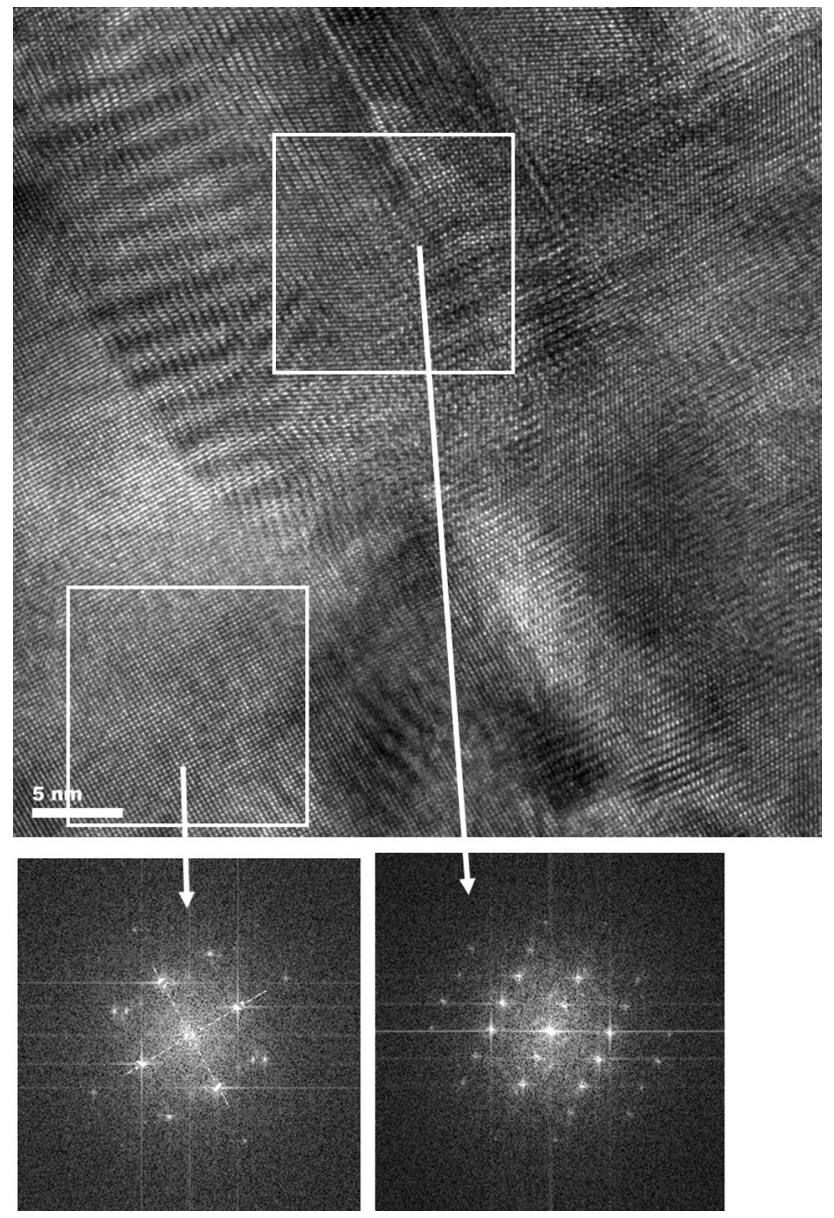

Fig. 7 HRTEM micrograph taken after KOBO extrusion and Fast Fourier Transform FFT from the marked areas of [0110] hcp and [001] bcc orientations

grains can be seen within the $\beta$ phase, being most probably the $\alpha$ particles (as was also observed in Fig. 3), formed during additional severe plastic deformation by cyclic forging. The bright particles are smaller particularly in the sample deformed at $200{ }^{\circ} \mathrm{C}$ which suggests the role of diffusion during deformation. The fine bright particles refined after the additional SPD after KOBO showed high scandium content, although their lithium content could not be measured using the EDS method.

Figure 9a shows an EBSD orientation map of the sample after the KOBO extrusion and $20 \times$ cyclic forging at $200{ }^{\circ} \mathrm{C}$. Satisfactory diffraction pattern indexing was obtained merely for the hcp $\alpha$ phase, while the orientation of individual $\beta$ bcc grains was also found. The $\alpha$ grains formed an elongated, while the $\beta$ phase occurred between them. In addition, very fine $\alpha$ grains were identified in the $\beta$ areas, similarly to that in Fig. 8. The average size of the larger $\alpha$ grains found in elongated areas, calculated from the EBSD result, was about $1 \mu \mathrm{m}$. The fine $\alpha$ grain areas detected in the $\beta$ regions (from which only single orientations were collected) confirmed
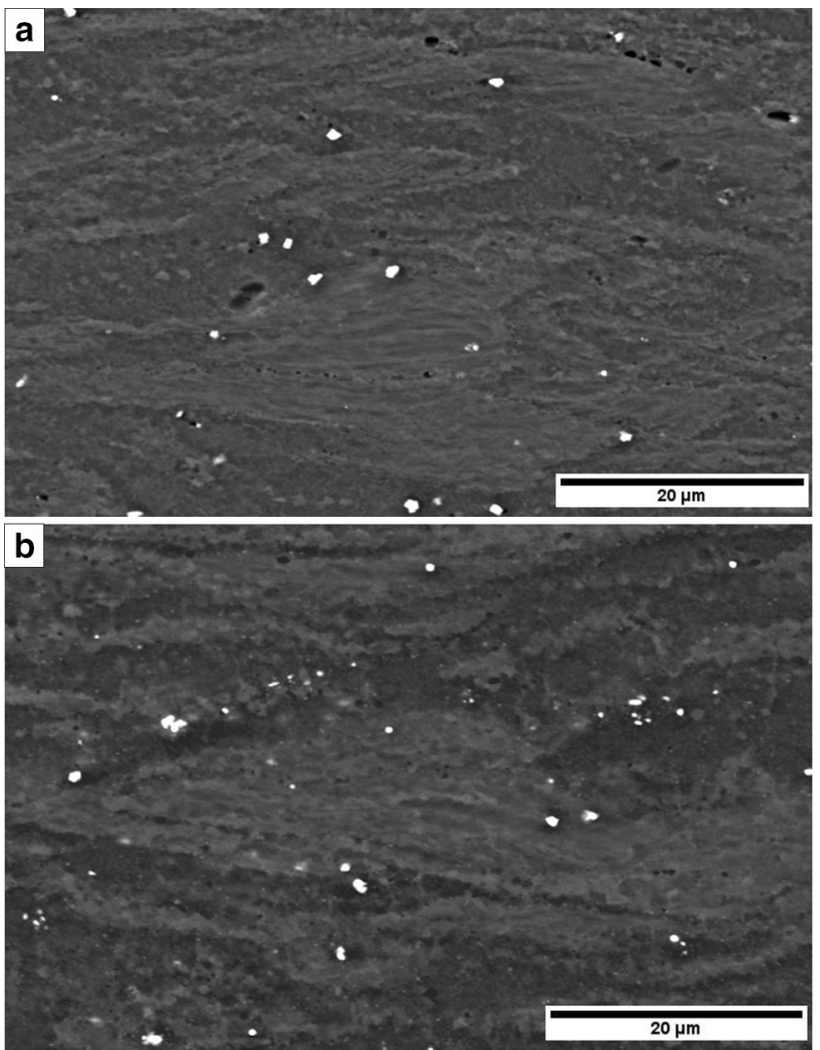

Fig. 8 SEM BSE images from the samples deformed after KOBO and additionally by 20 forging cycles at $\mathbf{a} 150{ }^{\circ} \mathrm{C}$ and $\mathbf{b}$ at $200{ }^{\circ} \mathrm{C}$

its formation after SPD as was also observed using SEM and TEM. Unfortunately, this phenomenon and additional oxidation of $\beta$ areas due to higher lithium content disturbed obtaining good quality electron diffractions and the measurement of the size of $\beta$ grains using the EBSD method. Nevertheless, the size of $\beta$ grains could be evaluated using TEM. The distribution of colors of individual $\alpha$ grains shows advantage of the red shade grains indicating privileged 0001 orientation of the $\alpha$ grain which results from the colors given for a basic crystallographic triangle shown in the corner of Fig. 9a. It was confirmed by the calculated 0001 pole figure from the EBSD data as presented in Fig. 9c. Similar type of texture with the strong [0001] texture component was also observed for $\mathrm{Mg}-\mathrm{Li}$ base alloys after rolling and rolling and annealing [42], after extrusion [39] or ECAP [40].

Figure 10 shows a TEM micrograph and SADP of the sample extruded using $\mathrm{KOBO}$ and additionally deformed with 20 forging cycles at $200{ }^{\circ} \mathrm{C}$. Very fine, (below $1 \mu \mathrm{m}$ ) dark and bright grains different from those observed only after KOBO extrusion were photographed. The six fold symmetry of the diffraction pattern and high intensity spots can be indexed according to the [1111] orientation of the bcc $\beta$ phase as results from the SADP taken from the central dark grain of the image. However, there are other diffraction 
Fig. 9 a Inverse pole figure (IPF) map acquired from the sample after KOBO extrusion and $\times 20$ cyclic forging at $200{ }^{\circ} \mathrm{C}$. The low and high angle grain boundaries, with misorientation angles lower and higher than $15^{\circ}$, are indicated by white and black colors, respectively. b 0001 pole figure from $\mathrm{Mg}$ rich phase and $\mathbf{c}$ grain size distribution

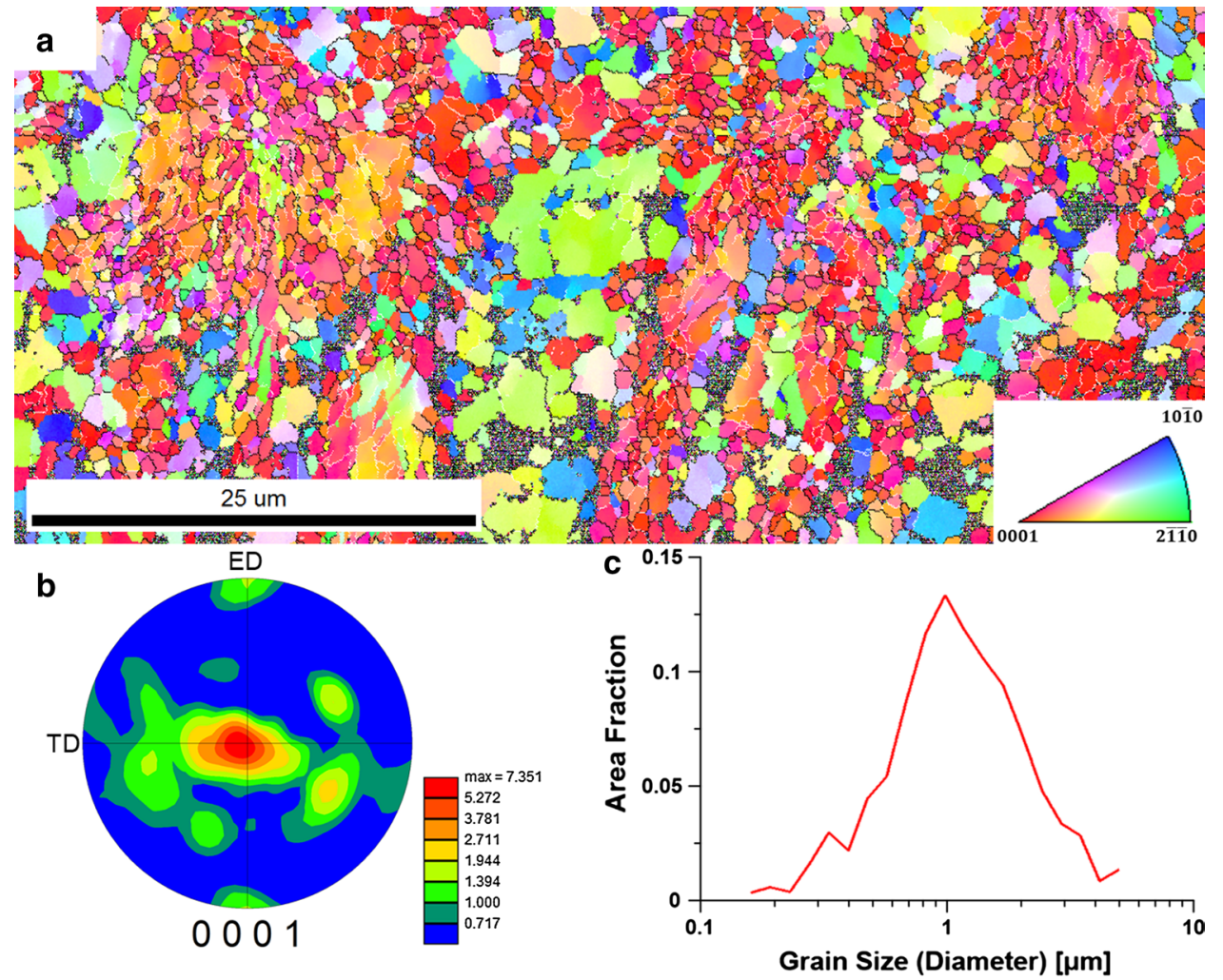

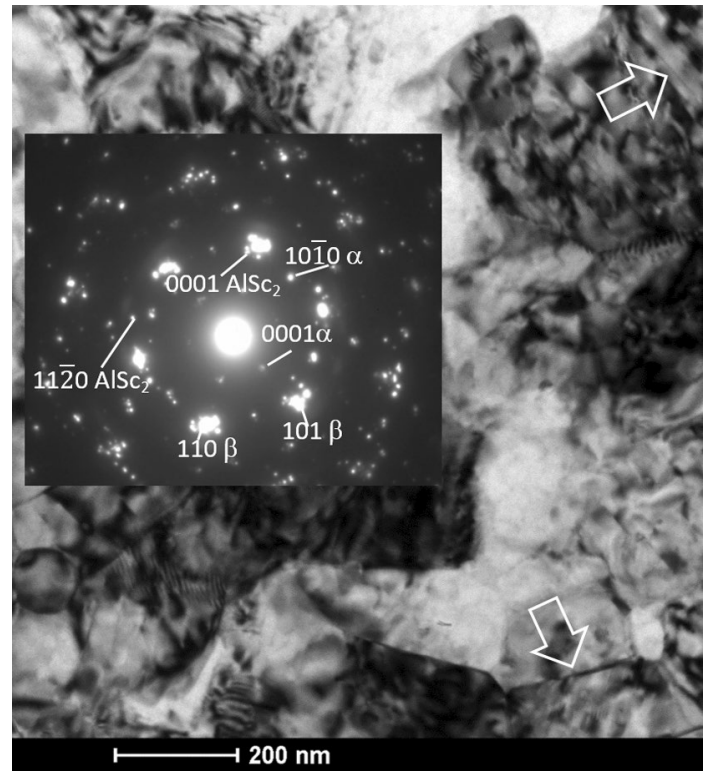

Fig. 10 TEM Bright Field BF micrograph from the sample deformed after KOBO by 20 forging cycles at $200{ }^{\circ} \mathrm{C}$ and SADP as an insert. Indexing of SADP placed as an insert shows [ $\left.\begin{array}{ll}1 & 11\end{array}\right]$ zone axis $\beta$, [0110] zone axis $\alpha$ and [11100] zone axis hcp $\mathrm{AlSc}_{2}$ orientations. Arrows shows very fine twin like features of several nm thickness systems of six fold symmetry that can be indexed according to 3 variants of [0110] zone axis orientations of the hcp $\alpha$ phase. The system of weaker spots indexed as [11100] zone axis of hcp $\mathrm{AlSc}_{2}$ orientations was also observed in Fig. 6. The densely packed planes of $0002 \mathrm{hcp} \alpha$ phase are rotated by a few degrees around the $\overline{1} 11 \beta$ axis in relation to the ideal orientation $\{0002\}$ hcp II $\{110\}$ bcc. Very fine parallel objects can be seen in the micrograph of Fig. 10 resembling twins several $\mathrm{nm}$ thick, parallel to $\{10 \overline{1} 0\}$ planes of the $\alpha$ phase as results from the SADP placed as insert. They can be interpreted as nanotwins, however no twin relation was found neither in the diffraction pattern nor using EBSD studies. Twins were observed in $\mathrm{Mg}-\mathrm{Li}$ [40, 42] and $\mathrm{Mg}-\mathrm{Sc}$ [23] alloys with $\{10 \overline{1} 2\}$ twinning plane and it is likely that they form in the investigated alloys, however they could not be confirmed using SADP.

The coexistence of bcc and hcp structures within the $\beta$ bcc grains in the samples deformed by KOBO extrusion and cyclic forging was in accordance with by the HRTEM micrograph shown in Fig. 11, where the fragment of $\beta$ bcc phase of the [1111] orientation and the hcp $\alpha$ phase at zone axis corresponding to [0110] hcp (the same as in Fig. 10) can be seen at higher magnification. Fast Fourier transform FFT from the marked areas shown in Fig. 11 confirms indexing of Fig. 10 and corresponds to [1111] $\beta$ and [01 $\overline{10}$ ] of the hep $\alpha$ phase from the areas marked by white squares. A very high density of dislocations on (0001) hcp $\alpha$ planes can be clearly seen 


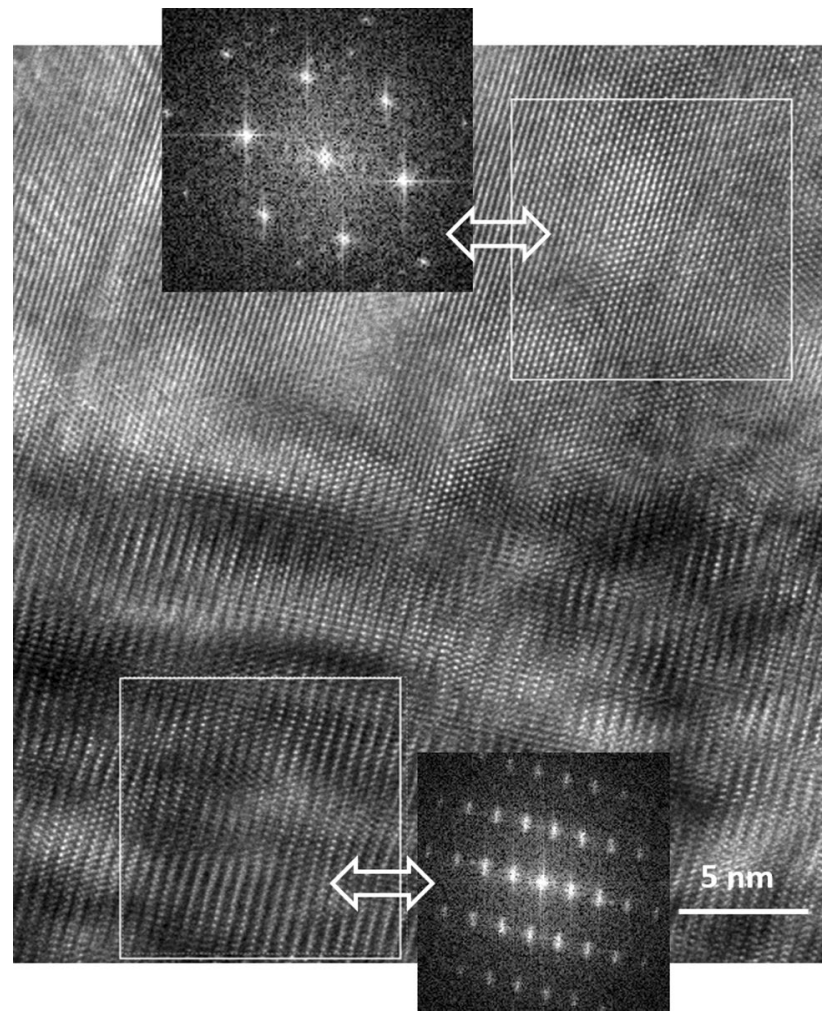

Fig. 11 HRTEM micrograph taken after KOBO extrusion and additional 20 forging cycles at $200{ }^{\circ} \mathrm{C}$. FFT from the marked areas corresponding to [0110] hcp and [001] bcc are shown as inserts

and its high frequency causes the diffusion of FFT points in the $<10 \overline{10}\rangle$ direction. They form most probably during the $\mathrm{bcc} \rightarrow \mathrm{hcp}$ strain induced and diffusion assisted transformation reported earlier [28, 32, 35].

Figure 12 presents a fragment of hcp $\alpha$ large grain at $[\overline{1}$ $10 \overline{2}$ ] zone axis orientation (as results from the SADP shown as insert) with fine (visible as dark) subgrains with high density of dislocations. Some bright particles partially etched in spite of FIB thinning technique can also be seen. They are most probably MgSc intermetallic particles of the cubic phase at [ $\overline{1} 11]$ zone axis orientation visible as bright ones in the dark field taken using 110 cubic $\mathrm{MgSc}$ phase reflection (Fig. 12b). Fine intermetallic particles are often located at the $\alpha$ hcp grain boundaries also seen in the SEM micrograph of Figs. 3 and 8. The dark field DF micrograph taken using the $110 \mathrm{MgSc}$ cubic intermetallic phase reflection shows that these particles are present not only as separate ones but also as a thin film at subgrain boundaries. The precipitates of $\mathrm{AlSc}_{2}$ phase did not form within the hcp $\alpha$ phase at smaller content of Li.

Figure 13 shows the TEM micrograph and SADP as insert taken of the sample deformed with the KOBO extrusion followed by 20 forging cycles at $200{ }^{\circ} \mathrm{C}$. Fine grains of size of a few hundred $\mathrm{nm}$ and relatively high dislocation density
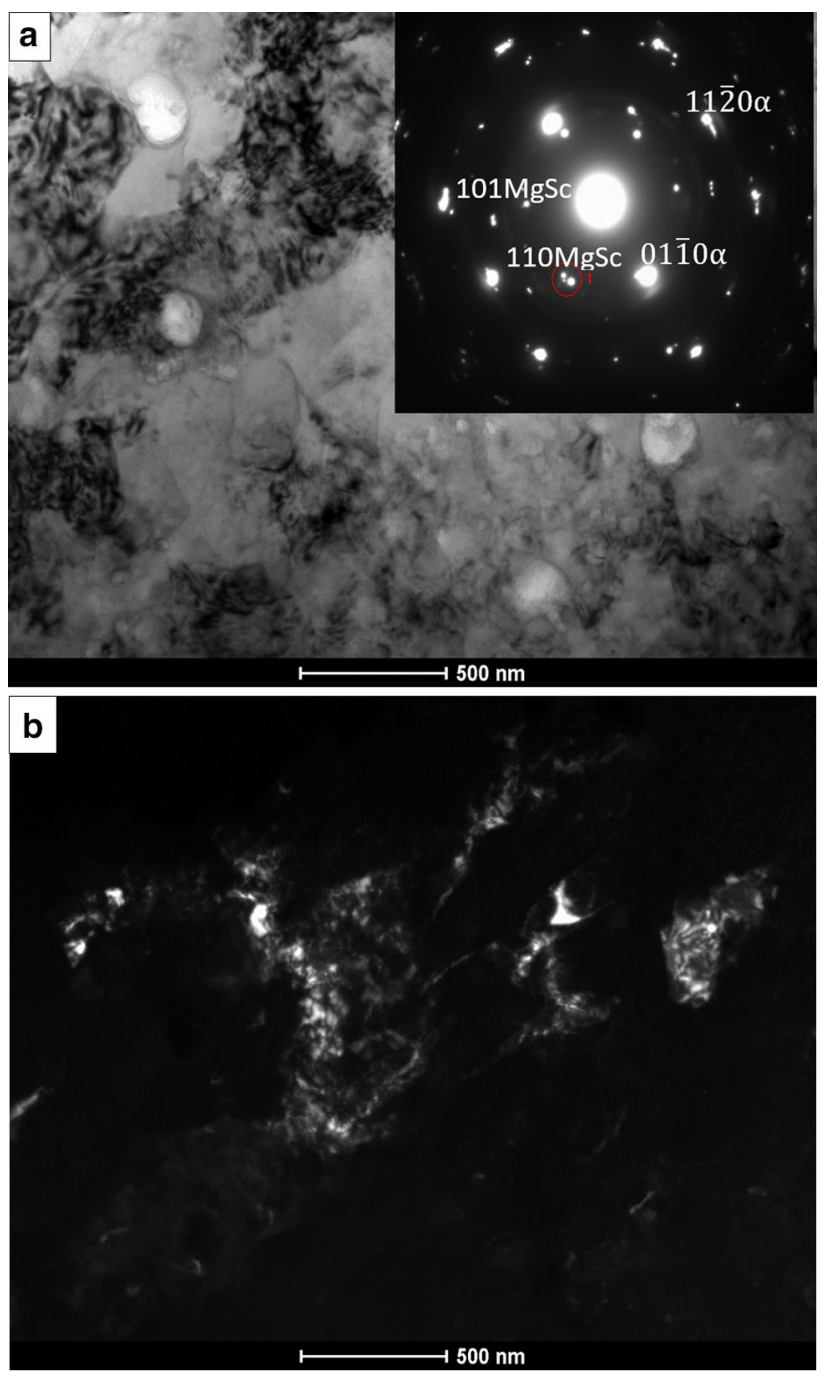

Fig. 12 a TEM Bright field BF micrograph from the sample deformed after $\mathrm{KOBO}$ by 20 forging cycles at $150{ }^{\circ} \mathrm{C}$; SADP as an insert shows hcp $\alpha$ phase at $\left[\begin{array}{ll}110 & \overline{2}\end{array}\right]$ zone axis orientation and $\mathrm{MgSc}$ cubic phase at [1111] zone axis orientation; b Dark field (DF) micrograph from the same area as in (a) taken using marked 110 cubic $\mathrm{MgSc}$ phase reflection

can be seen also in other micrographs of the samples after this type of SPD. The diffraction pattern can be indexed as two bcc $\beta$ [111] zone axis orientations twisted around the [111] direction by $33^{\circ}$. It indicates a relatively high misorientation of the bcc $\beta$ grains in a small area. In addition, the SADP demonstrates fine reflections from the intermetallic phase lattice identified as the hexagonal $\mathrm{AlSc}_{2}$ phase at $[\overline{1}$ 101] zone axis orientation. This indicates that there are at least two kinds of primary precipitates i.e. cubic $\mathrm{MgSc}$ forming most frequently within the hcp $\alpha$ grains and hcp $\mathrm{AlSc}_{2}$ ones observed in the bcc $\beta$ phase of higher lithium content. It suggests that the addition of scandium increases a variety of fine particle formation in the $\mathrm{Mg}-\mathrm{Li}-\mathrm{Al}$ alloys, where 


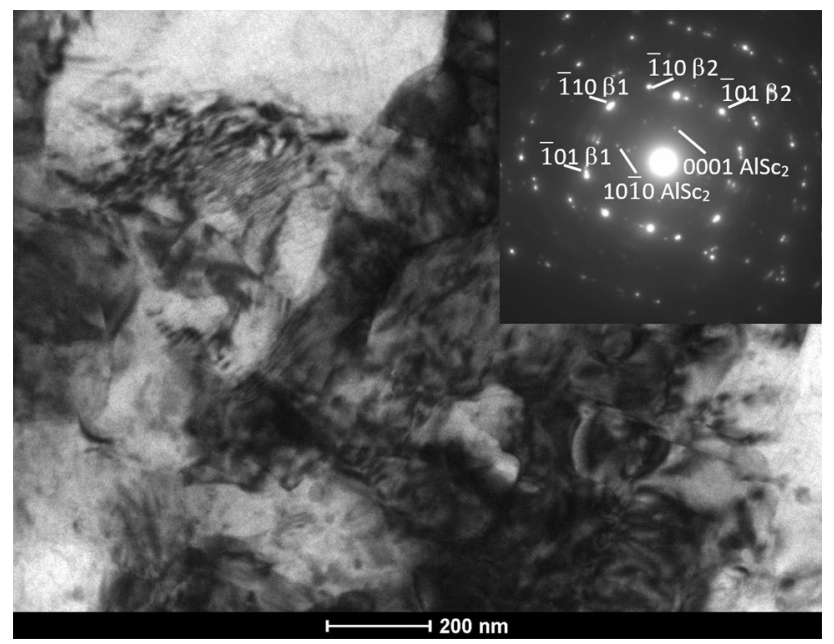

Fig. 13 TEM micrograph and SADP as an insert from the sample after 20 forging cycles at $200{ }^{\circ} \mathrm{C}$. SADP was indexed as bcc $\beta$ [111] zone axis orientations twisted around [111] direction by $33^{\circ}$ and hexagonal $\mathrm{AlSc}_{2}$ phase at [ $\left.\overline{1} 10 \overline{1}\right]$ zone axis orientation

the precipitation of $\mathrm{MgAlLi}_{2}$ phase was the most frequently observed [3, 4].

\section{Conclusions}

1. KOBO type extrusion caused significant grain refinement of $\alpha+\beta$ dual phase in Mg-9Li-2Al-0.5Sc alloys down to range $1-10 \mu \mathrm{m}$ for hcp $\alpha$ phase and $1-5 \mu \mathrm{m}$ for $\beta$ phase as results from EBSD studies. At that stage tensile strength of $160 \mathrm{MPa}$ and elongation of $35 \%$ was attained. Fine parallel objects similar to twins several nm big were observed within hcp $\alpha$ phase, although they were not confirmed using electron diffraction studies. Additional deformation by cyclic forging alternatively from perpendicular directions caused formation of much finer grains identified using TEM with average size of a few hundred $\mathrm{nm}$ and using EBSD close to $1 \mu \mathrm{m}$. The tensile strength increased after that operation above 200 MPa and elongation to $40 \%$, which belonged to the highest values observed for dual phase $\mathrm{Mg}-\mathrm{Li}$ based alloys. Strong texture with 0001 plane parallel to forging directions was observed after application of additional deformation by cyclic forging.

2. Additional precipitates of size below $1 \mu \mathrm{m}$ at $\alpha / \beta$ interfaces or more frequently within $\beta$ phase were observed after SPD. They were identified as hcp $\mathrm{AlSc}_{2}$ phase and $\mathrm{MgSc}$ cubic structure particles existing more often within hcp $\alpha$ phase. Within $\beta$ phase grains, fine particles of hcp $\alpha$ phase were observed, which formed due to diffusion assisted SPD deformation. Amount of hcp $\alpha$ phase increased after SPD up to $70 \%$ compared with ini- tial 40\%. HRTEM allowed identification of high density of defects at $\alpha / \beta$ interfaces on 0001 planes, confirming their promoting role in hcp phase formation during SPD.

Acknowledgements The financial support of the National Science Center (NCN) under Project No. 2014/15/B/ST8/03184 is gratefully acknowledged.

Open Access This article is distributed under the terms of the Creative Commons Attribution 4.0 International License (http://creativeco mmons.org/licenses/by/4.0/), which permits unrestricted use, distribution, and reproduction in any medium, provided you give appropriate credit to the original author(s) and the source, provide a link to the Creative Commons license, and indicate if changes were made.

\section{References}

1. R. Wu, Y. Yan, G. Wang, L.E. Murr, W. Han, Z. Zhang, M. Zhang, Int. Mater. Rev. 60(2), 65 (2015)

2. H. Haferkamp, R. Boehm, U. Holzkamp, C. Jaschik, V. Kaese, M. Niemeyer, Mater. Trans. 42(7), 1160 (2001)

3. J.B. Clark, L. Sturkey, J. Inst. Met. 86(6), 272 (1958)

4. C.J. Ma, D. Zhang, W.B. Hu, T. Nonferr, Met. Soc. 9(4), 772 (1999)

5. S.R. Agnew, J.A. Horton, M.H. Yoo, Metall. Mater. Trans. A 33(3), 851 (2002)

6. G.H. Park, J.T. Kim, H.J. Park, Y.S. Kim, H.J. Jeong, N. Lee, Y. Seo, J.Y. Suh, H.T. Son, W.M. Wang, J.M. Park, K.B. Kim, J. Alloys Compd. 680, 116 (2016)

7. T. Zhang, T. Tokunaga, M. Ohno, R. Wu, M. Zhang, K. Matsuura, Mater. Sci. Eng. A 737, 61 (2018)

8. J. Zhao, J. Zhang, W. Liu, G. Wu, L. Zhang, Mater. Sci. Eng. A 650, 240 (2016)

9. F.R. Cao, G.Q. Xue, B.J. Zhou, S.C. Wang, Met. Mater. Int. 25(3), 570 (2019)

10. J. Dutkiewicz, Ł. Rogal, D. Kalita, P. Fima, J. Alloys Compd. 784, 686 (2019)

11. S. Kudela, A. Pawelek, Z. Ranachowski, A. Piatkowski, A.J.R. Kudela, P. Ranachowski, Kovove Mater. 49(4), 271 (2011)

12. X. Liu, G. Du, R. Wu, Z. Niu, M. Zhang, J. Alloys Compd. 509(39), 9558 (2011)

13. X. Zhou, R. Liu, Q. Liu, H. Zhou, Met. Mater. Int. (2019). https ://doi.org/10.1007/s12540-019-00263-w

14. X. Zhou, Q. Liu, R. Liu, H. Zhou, Met. Mater. Int. 24, 1359 (2018)

15. L. Yangmin, P. Xiaodong, H. Faping, W. Guobing, X. Weidong, L. Junwei, Y. Yan, L. Mengluan, W. Xuemei, Rare Met. Mater. Eng. 46(7), 1775 (2017)

16. F. Cao, G. Xue, G. Xu, Mater. Sci. Eng. A 704, 360 (2017)

17. J. Zhang, Y. Zhang, G. Wu, W. Liu, L. Zhang, W. Ding, Mater. Sci. Eng. A 621, 198 (2015)

18. Z. Zhenyu, P. Xiaodong, Y. Lei, Y. Yan, L. Yangmin, M. Yi, L. Mengluan, Rare Met. Mater. Eng. 46(8), 2055 (2017)

19. R.J.M. Hooper, Z.L. Bryan, M.V. Manuel, Metall. Mater. Trans. A 45(1), 55 (2014)

20. K. Edalati, D. Akama, A. Nishio, S. Lee, Y. Yonenaga, J.M. Cubero-Sesin, Acta Mater. 69, 68 (2014)

21. G. Sha, X. Sun, T. Liu, Y. Zhu, T. Yu, J. Mater. Sci. Technol. 27(8), 753 (2011)

22. H.Y. Wu, Z.W. Gao, J.Y. Lin, C.H. Chiu, J. Alloys Compd. 474(12), 158 (2009)

23. A. Kula, C.J. Silva, M. Niewczas, J. Alloys Compd. 727, 642 (2017) 
24. H. Matsunoshita, K. Edalati, M. Furui, Z. Horita, Mater. Sci. Eng. A 640, 443 (2015)

25. H.P. Yang, M.W. Fu, S. To, G.C. Wang, Mater. Des. 112, 151 (2016)

26. M. Furui, H. Kitamura, H. Anada, T.G. Langdon, Acta Mater. 55(3), 1083 (2007)

27. J. Dutkiewicz, S. Rusz, D. Kuc, O. Hilser, P. Pałka, G. Boczkal, Acta Metallurgica Slovaca 23(3), 215 (2017)

28. T. Liu, S.D. Wu, S.X. Li, P.J. Li, Mater. Sci. Eng. A 460, 499 (2007)

29. Y. Tang, W. Jia, X. Liu, Q. Le, Y. Zhang, Mater. Sci. Eng. A 675, 55 (2016)

30. M. Furui, C. Xu, T. Aida, M. Inoue, H. Anada, T.G. Langdon, Mater. Sci. Eng. A 410, 439 (2005)

31. Y. Yoshida, L. Cisar, S. Kamado, Y. Kojima, Mater. Trans. 43(10), 2419 (2002)

32. J. Dutkiewicz, P. Bobrowski, S. Rusz, O. Hilser, T.A. Tański, W. Borek, M. Łagoda, P. Ostachowski, P. Pałka, G. Boczkal, D. Kuc, T. Mikuszewski, Met. Mater. Int. 24, 1077 (2018)

33. A. Korbel, J. Pospiech, W. Bochniak, A. Tarasek, P. Ostachowski, J. Bonarski, Int. J. Mater. Res. 102, 464 (2011)

34. I. Bednarczyk, D. Kuc, A. Tomaszewska, A. Mrugała, Arch. Metall. Mater. 62, 545 (2017)

35. W. Bochniak, A. Brzostowicz, Arch. Metall. Mater. 55(2), 587 (2010)
36. W. Bochniak, A. Korbel, Eng. Trans. 47(3-4), 351 (1999)

37. S. Ziółkiewicz, M. Gąsiorkiewicz, P. Wesołowska, S. Szczepanik, R. Szyndler, Met. Form. Metali 23(3), 149 (2012)

38. H. Somekawa, T. Tsuru, Scripta Mater. 130, 114 (2017)

39. M.A. Kumar, I.J. Beyerlein, R.A. Lebensohn, C.N. Tomé, Mater. Sci. Eng. A 706, 295 (2017)

40. Y. Zou, J. Li, H. Wang, K. An, M. Zhang, D. Chen, Z. Zhang, J. Alloys Compd. 685, 331 (2016)

41. Z. Chen, Z. Li, C. Yu, Mater. Sci. Eng. A 528, 961 (2011)

42. Y. Zou, L. Zhang, H. Wang, X. Tong, M. Zhang, Z. Zhang, J. Alloys Compd. 669, 72 (2016)

43. Y. Zeng, B. Jiang, Q.R. Yang, G.F. Quan, J.J. He, Z.T. Jiang, F.S. Pan, Mater. Sci. Eng. A 700, 59 (2017)

44. G.J. Shen, B.J. Duggan, Metall. Mater. Trans. A 38(10), 2593 (2007)

45. Y. Zou, Y. Zhang, Y. Zhao, S.S. Xu, H. Guo, M.L. Zhang, Z.W. Zhang, Magnesium Technology (Springer, Cham, 2016), pp. 263-266

46. V. Kumar, G.R. Shekhar, R. Balasubramaniam, K. Balani, Mater. Sci. Eng. A 547, 38 (2012)

Publisher's Note Springer Nature remains neutral with regard to jurisdictional claims in published maps and institutional affiliations. 